\title{
BMJ Open Quality Person-specific outcome measure (PSO) for use in primary and community care
}

\author{
Tim Benson (D) 1,2
}

To cite: Benson T. Person-specific outcome measure (PSO) for use in primary and community care. BMJ Open Quality 2021;10:e001379. doi:10.1136/ bmjoq-2021-001379

Received 30 January 2021 Revised 24 March 2021 Accepted 19 April 2021

\section{Check for updates}

(c) Author(s) (or their employer(s)) 2021. Re-use permitted under CC BY-NC. No commercial re-use. See rights and permissions. Published by BMJ.

${ }^{1}$ R-Outcomes, Newbury, UK ${ }^{2}$ Institute of Health Informatics, University College London, London, UK

Correspondence to Mr Tim Benson;

tim.benson@r-outcomes.com

\section{BACKGROUND}

Patient-reported outcome and experience measures (PROMs and PREMs) fall into three broad categories: condition-specific measures, which are applicable to patients with specific conditions only; generic measures, which apply to all types of patient; and individualised or person-specific measures (iPROMs), which let people identify issues that are most important to them. ${ }^{12}$ Thousands of condition-specific measures have been developed mainly for use in clinical trials; standardised generic measures are widely used in evaluation, for quality improvement and for allocating resources between different groups. However, fewer individualised measures have been developed, although there is increasing awareness of their value in tailoring personalised care in domains such as social prescribing. Individualised measures need to be used alongside generic or condition-specific measures because every patient has their own set of priorities and some are much easier to resolve than others.

Several individualised measures were developed during the 1990s, such as SEIQOL (Schedule for Evaluation of Individual Quality Of Life), ${ }^{3}$ PGI (Patient Generated Index) ${ }^{4}$ and MYMOP (Measure Yourself Medical Outcome Profile). ${ }^{5}$ MYMOP evolved into MYCaW (Measure Yourself Concerns and Wellbeing), which is a little simpler, with two concerns plus well-being. ${ }^{67}$

At the request of customers working in social prescribing projects, at R-Outcomes we used MYMOP and then MYCaW alongside our other measures. This identified a number of issues, which led to the development of a new iPROM, the person-specific outcome (PSO) measure, which is described here.

\section{Development of the measure}

We designed PSO to work in a way similar to other measures in the R-Outcomes family of short generic PROMs and PREMs. ${ }^{8}$ Common core characteristics of all these measures include:

1. Brevity and low reading age.
2. Quick and easy to use and understand.

3. Four response options.

4. Optional use of emojis (smiley faces) and colour (green, yellow, orange red) to help understanding.

5. Mean scores for a population are reported on a $0-100$ scale.

6. A high score is always good, low is always bad.

For individuals, the PSO uses the same response options as the howRu health status measure. ${ }^{9}$ Extreme scores 0, Quite a lot scores 1, A little scores 2 and None scores 3. In reports on individuals, the original patient-specific text and score is used for each issue.

The questions are typically asked at first meeting with the patient and on follow-up. The final version, showing both first meeting and follow-up questions, is shown in figure 1 .

On follow-up, the original issue(s) are digitally prepopulated with the issue texts recorded at first meeting. Patients are asked to record their current level of concern. The questions can be asked face-to-face or by telephone. We do not recommend asking these questions at first meeting without any staff involvement, because patients often seek advice about what issues to record.

When reporting the results for a cohort, the mean scores for issue \#1 and issue \#2 are presented on a $0-100$ scale (by multiplying by 100 and dividing by 3 ). Mean scores are usually shown without decimal points. A summary score is not calculated.

For example:

First meeting (issue \#1) mean score $=30$.

Follow-up (issue \#1) mean score $=70$.

Mean change $($ issue $\# 1)=40$.

\section{DISCUSSION}

The PSO is an evolutionary step forward. We acknowledge that our ideas have been influenced by our experience using earlier individualised outcome measures but have taken care not to infringe copyright.

Individualised outcome measures are particularly useful when people are living 


At first meeting
List one or two issues you would like help with
Issue \#1
Issue \#2
How much concern does each issue cause you?
Issue \#1
Issue \#2
At follow-up

Figure 1 Person-specific outcome (PSO) measure, showing first meeting and follow-up questions.

with multiple long-term conditions and it is important to help them adapt. It helps health and care staff to identify and focus on what matters most to their patients.

Users may wish to restrict what sort of issues may be listed. For example, in social prescribing it may be appropriate to suggest that patients list issues that social prescribing link workers may be expected to help with, rather than medical issues (such as finding a cure for cancer or diabetes) or economic issues (such as winning the lottery) that are outside their scope.

However, because people can prioritise very different things, we recommend that iPROMs be used alongside generic PROMs and PREMs. Preliminary findings suggest that changes in PSO scores correlate strongly with changes in well-being (as measured by the Personal Well-being Score (PWS) $),{ }^{10}$ but not with changes in health status ${ }^{9}$ or health confidence. ${ }^{11}$

The main technical issue in using the PSO, in common with other iPROMs, is digital prepopulation of the follow-up survey with the issues recorded on the initial survey for the same patient.

The PSO avoids, when used with other R-Outcomes measures, several issues encountered with other iPROMs we have used, such as MYMOP and MYCaW. The main differences are mentioned below.

PSO is short and quick to use. It has four response options, which are labelled with words and coloured emojis, not numbers. Mean scores for a population use a 0-100 scale with a high score always being high. This means that reported improvement is signified by a positive number. A well-being question is not part of PSO, because patients are usually asked about their well-being using a generic PROM such as PWS.

PSO has been developed and piloted with social prescribing link workers. Our experience of the present final version is still limited, which is why this is a short report, not a full paper. We will publish a full report of the validation and practical experience using PSO when we have enough data using the present version.

PSO is released under the Creative Commons Attribution-NonCommercial-ShareAlike V.4.0 international licence (CC-BY-NC-SA). This means that it can be used in any non-commercial way, such as for education or small short-term projects. If you wish to use in any other way, please contact R-Outcomes.

\section{CONCLUSION}

The PSO measure is a new individualised outcome measure, which is short and easy to use. It has been designed to be used alongside other R-Outcomes measures. It is well suited to primary and community care, including social prescribing, where a personalised approach is needed, and people present with a wide variety of issues.

Correction notice This article has been corrected since it was published. Acknowledgement section has been updated.

Twitter Tim Benson @timbenson

Acknowledgements We are grateful to social prescribing link workers in Hampshire, Berkshire and Surrey who contributed to our understanding of the requirements and the design, and to patients who completed early versions.

Contributors TB is wholly responsible for the content.

Funding The authors have not declared a specific grant for this research from any funding agency in the public, commercial or not-for-profit sectors.

Competing interests TB is a shareholder in R-Outcomes, which owns the copyright of the person-specific outcome (PSO) measure.

Patient and public involvement Patients and/or the public were not involved in the design, or conduct, or reporting, or dissemination plans of this research.

Patient consent for publication Not required.

Provenance and peer review Not commissioned; externally peer reviewed.

Open access This is an open access article distributed in accordance with the Creative Commons Attribution Non Commercial (CC BY-NC 4.0) license, which permits others to distribute, remix, adapt, build upon this work non-commercially, and license their derivative works on different terms, provided the original work is properly cited, appropriate credit is given, any changes made indicated, and the use is non-commercial. See: http://creativecommons.org/licenses/by-nc/4.0/.

ORCID iD

Tim Benson http://orcid.org/0000-0002-2101-1353

\section{REFERENCES}

1 Dijkers MP. Individualization in quality of life measurement: instruments and approaches. Arch Phys Med Rehabil 2003;84:S3-14.

2 Porter I, Gonçalves-Bradley D, Ricci-Cabello I, et al. Framework and guidance for implementing patient-reported outcomes in clinical practice: evidence, challenges and opportunities. J Comp Eff Res 2016;5:507-19.

3 Browne JP, O'Boyle CA, McGee HM, et al. Individual quality of life in the healthy elderly. Qual Life Res 1994;3:235-44.

4 Ruta DA, Garratt AM, Leng M, et al. A new approach to the measurement of quality of life. The Patient-Generated index. Med Care 1994;32:1109-26.

5 Paterson C. Measuring outcomes in primary care: a patient generated measure, MYMOP, compared with the SF-36 health survey. BMJ 1996;312:1016-20.

6 Paterson C, Thomas K, Manasse A, et al. Measure yourself concerns and wellbeing (MYCaW): an individualised questionnaire for evaluating outcome in cancer support care that includes complementary therapies. Complement Ther Med 2007;15:38-45. 
7 Polley MJ, Seers HE, Cooke HJ, et al. How to summarise and report written qualitative data from patients: a method for use in cancer support care. Support Care Cancer 2007;15:963-71

8 Benson T. Measure what we want: a taxonomy of short generic person-reported outcome and experience measures (PROMs and PREMs). BMJ Open Qual 2020;9:e000789.

9 Benson T, Sizmur S, Whatling J, et al. Evaluation of a new short generic measure of health status: howRu. Inform Prim Care 2010;18:89-101.
10 Benson T, Sladen J, Liles A, et al. Personal Wellbeing Score (PWS)-a short version of ONS4: development and validation in social prescribing. BMJ Open Qual 2019;8:e000394.

11 Benson T, Potts HWW, Bark P, et al. Development and initial testing of a health confidence score (HCS). BMJ Open Qual 2019;8:e000411. 